\section{Effect of seasonal variation in daylight on bilirubin level in premature infants}

It has been shown in several recent studies that exposure to light has some influence on serum bilirubin levels (Cremer, Perryman, and Richards, 1958; Lucey, 1970; Maisels, 1972). The question of the possible effect of environmental illumination on neonatal bilirubin levels was raised by Giunta and Rath (1969), who showed that a modest increase in environmental illumination had a significant effect in reducing hyperbilirubinaemia of prematurity.

The purpose of this paper is to study the effect of seasonai increase in daylight on the bilirubin level in premature infants.

\section{Patients and methods}

An alternate case series of 86 consecutive infants born between March 1971 and February 1972 at the University Central Hospital of Oulu, and weighing less than $2500 \mathrm{~g}$ at birth, were placed in incubators completely exposed except for nappies. The babies were treated in the same three rooms. The large double glazed windows in those rooms faced south. At darkness electric lights in the nursery were kept on only to allow nursing of the infants.

The patients were divided in two groups according to birth date. Light group: infants born from March 1971 to August 1971. During these 6 months the duration of daylight was 17 hours 52 minutes on average (range 10 to $22 \mathrm{~h}$ ) in Oulu (latitude $65^{\circ} 1^{\prime}$ ). Dark group: infants born from September 1971 to February 1972. During this period the average duration of daylight was 7 hours 32 minutes (range 3 to $14 \mathrm{~h}$ ).

Forty preterm infants were born during the light half of the year; 4 of them were excluded from the study (1 with Rh-immunization, 1 septicaemia, 1 E-trisomy, 1 dying of severe respiratory distress syndrome (RDS)).

Forty-six preterm infants were born during the dark half of the year. 6 of them were excluded (1 septicaemia, 2 severe hepatosis of pregnancy, 2 dying of severe RDS, 1 pneumonia and pneumothorax).

Blood Hb, Coombs's test, blood group, Rh-factor, and blood glucose were determined for each infant on the first postnatal day. Total serum bilirubin was determined at the ages of $2,4,6,8$, and 10 days with a modified Malloy-Evelyn micromethod.

Early feeding was started at 2 hours of age. The Table shows some clinical details of the patients under
TABLE

Comparison of groups

\begin{tabular}{l|c|c}
\hline & $\begin{array}{c}\text { 'Light group' } \\
\text { (no. = 36) }\end{array}$ & $\begin{array}{c}\text { 'Dark group' } \\
\text { (no. = 40) }\end{array}$ \\
\hline $\begin{array}{c}\text { Gestational age (w) } \\
\text { (mean } \pm \text { SD) }\end{array}$ & $\begin{array}{c}33 \cdot 6 \pm 2 \cdot 7 \\
1919 \pm 387\end{array}$ & $\begin{array}{c}34 \cdot 2 \pm 2 \cdot 4 \\
1974 \pm 304\end{array}$ \\
$\begin{array}{c}\text { Birthweight (g) (mean } \pm \text { SD) } \\
\text { Infants with hypoglycaemia } \\
\text { (blood glucose }<20 \mathrm{mg} / 100 \mathrm{ml})\end{array}$ & 5 & 4 \\
$\begin{array}{c}\text { Infants with respiratory } \\
\text { distress syndrome }\end{array}$ & 5 & 5 \\
\hline
\end{tabular}

study. The groups were comparable in gestational age, birthweight, and incidence of RDS or neonatal hypoglycaemia. Infusions (10 or $20 \%$ glucose) were given to the infants requiring treatment for RDS and those with low blood glucose or an inability to tolerate early gastric feeding. Exchange transfusion was done if total serum bilirubin after 3 days of age was $>340 \mu \mathrm{mol} / 1$.

\section{Results}

The total serum bilirubin values of the two groups for each of the 5 days studied are shown in the Fig. The mean values were all lower in the light group and from the age of 4 days the difference between the two groups was significant $(P>0 \cdot 05)$. In the light group only 4 infants developed total bilirubin levels higher than $255 \mu \mathrm{mol} / 1$ while 10 did so in the dark group. 2 infants required exchange transfusion in the light group and 4 in the dark group.

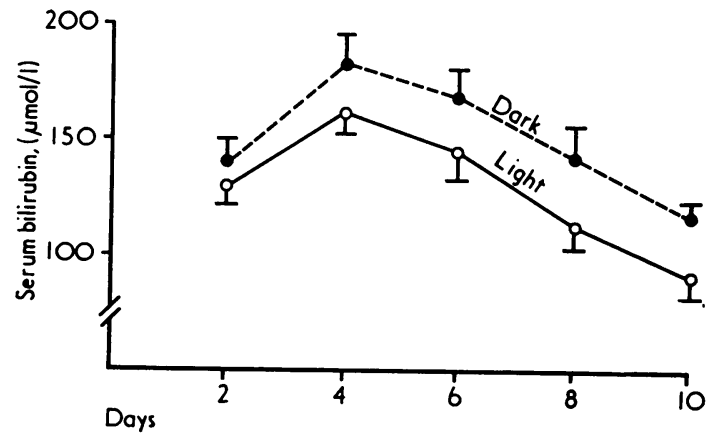

FIG.-Total serum bilirubin values (mean $\pm \mathrm{SE}$ ) during the first 10 days in each group. Significance of difference: days 4,6 , and 10, $P<0.05 ;$ day $8, P<0 \cdot 01$. 


\section{Discussion}

This study indicated that the total serum bilirubin levels of preterm infants during the first 10-day period of postnatal life were lower from March to August than from September to February in an area located far north (latitude $65^{\circ} 1^{\prime}$ ). The data of Giunta and Rath (1969) showed that infants exposed to environmental light averaging only 90 foot-candles had lower serum bilirubin levels than infants nursed in environmental light averaging 10 foot-candles. Thus, intensity and duration of light in any nursery may play a significant role in explaining the considerable variation in the incidence of hyperbilirubinaemia from one nursery to another (Lucey, 1960).

Compared with the levels of normal daylight, we have been working in relatively dark conditions in our nurseries. Giunta and Rath measured 5000 to 10000 foot-candles in direct sunlight and 100 to 1000 foot-candles in the shade. According to MacLeod and Stern (1972), the amount of illumination received by an infant varied from 15 to 2500 foot candles, depending upon the location in the nursery, the time of day, and the amount of sunlight.

In this study the babies were treated in incubators, where they were completely exposed except for nappies. In another study we found no seasonal variation in neonatal bilirubin levels of term babies nursed dressed and in cots (unpublished).

In our district (latitude $65^{\circ} 1^{\prime}$ ) the seasonal variation of illumination is extreme. The mean duration of daylight from March to August is twice as long as that from September to Febuary. This difference might explain the lower serum bilirubin levels of the preterm infants born during the light half of the year observed in this study, as well as the seasonal variation in neonatal hyperbilirubinaemia reported by Milby, Mitchell, and Freeman (1969).

This study shows that the natural light in a neonatal ward can have some effect in preventing hyperbilirubinaemia. This should be taken into consideration when designing nurseries.

\section{Summary}

The effect of daylight on the serum bilirubin level of preterm infants (birthweight $<2500 \mathrm{~g}$ ) during the first 10 days of life was studied in a district of Finland (Oulu, latitude $65^{\circ} 1^{\prime}$ ) with large seasonal variations in the length of daylight (range 3 to $22 \mathrm{~h}$ ). 86 preterm infants born consecutively during one calendar year were studied in incubators where they were completely exposed except for nappies.
A significantly lower bilirubin value from the fifth day of life onwards was recorded in the group of infants born during the light half of the year, compared with the infants born during the dark half of the year. Only 4 infants developed total bilirubin levels higher than $255 \mu \mathrm{mol} / 1$ in the 'light group', as compared with 10 in the 'dark group'. 2 infants in the light group required exchange transfusion, while 4 in the dark group did.

It is concluded that natural light conditions are of importance in the design of wards for newborn infants.

\section{REFERENCES}

Cremer, R. J., Perryman, P. W., and Richards, D. H. (1958) Influence of light on the hyperbilirubinaemia of infants. Lancet, 1, 1094.

Giunta, F., and Rath, J. (1969). Environmental illumination in prevention of hyperbilirubinemia of prematurity. Pediatrics, 44, 162.

Lucey, J. F. (1960). Hyperbilirubinemia of prematurity. Pediatrics, 25, 690.

Lucey, J. F. (1970). Phototherapy of jaundice, 1969. Bilirubin Metabolism in the Newborn. Birth Defects. Original Article Series, Vol. 6, No. 2, p. 63. Ed. by D. Bergsma and D. Y. Hsia. Williams and Wilkins, Baltimore.

MacLeod, P., and Stern, L. (1972). Natural variations in environmental illumination in a newborn nursery. Pediatrics, 50, 131.

Maisels, M. J. (1972). Bilirubin: on understanding and influencing its metabolism in the newborn infant. Pediatric Clinics of North America, 19, 447.

Milby, T. H., Mitchell, J. E., and Freeman, T. S. (1969). Seasonal neonatal hyperbilirubinemia. Pediatrics, 43, 601.

I. Anttolainen, $\star$ S. Similä, and E. I. Wallgren Department of Paediatrics, Keski-Pohjanmaa Central Hospital, Kokkola, and Departments of Paediatrics at the Universities of Helsinki and Oulu, Finland.*

^Correspondence to Dr. I. Anttolainen, Department of Paediatrics, Keski-Pohjanmaa Central Hospital, SF-67200 Kokkola, Finland.

\section{Sexual precocity associated with a hypothalamic tumour}

\section{Effects of sex hormone therapy}

The precocious onset of puberty is defined as the appearance of secondary sexual characteristics before the age of 10 years in a boy and 8 years in a girl (Seckel, 1946). The case we describe here is remarkable for its very early age of onset (under one year), its association with a hypothalamic tumour, and the unusual pattern of suppressibility of the greatly raised gonadotrophin and testosterone levels by oestrogen therapy. The results are considered 